\title{
EMPLOYING PHARMACOKINETIC AND PHARMACODYNAMIC PRINCIPLES TO OPTIMIZE ANTIMICROBIAL TREATMENT IN THE FACE OF EMERGING RESISTANCE
}

\author{
Lauro Santos Filho', Joseph L. Kuti², David P. Nicolau ${ }^{2}$ \\ ${ }^{1}$ Departamento de Ciências Farmacêuticas, Universidade Federal da Paraíba, João Pessoa, PB, Brasil; ${ }^{2}$ Center for Anti-Infective \\ Research and Development, Hartford Hospital, Hartford, CT, USA
}

Submitted: December 08, 2006; Approved: February 23, 2007.

\begin{abstract}
Antimicrobial efficacy in vivo is not exclusively defined by the activity of an antibiotic as determined in the in vitro susceptibility test. Knowledge of the pharmacokinetics and pharmacodynamics of antimicrobials and all phenomena occurring between antimicrobial agents and microorganisms is imperative. The pharmacodynamic (PD) parameters most often used in studies of antibiotic effect include the following relationships: the maximum free concentration $\left(f \mathrm{C}_{\max }\right)$ to minimum inhibitory concentration (MIC) ratio, the free area under the curve ( $f \mathrm{AUC} / \mathrm{MIC})$ ratio and the duration of time the free concentration exceeds the MIC ( $f \mathrm{~T}>\mathrm{MIC}$ ). Utilization of known pharmacokinetic/ pharmacodynamic surrogate relationships should help to optimize treatment outcome, especially in the face of emerging resistance among Gram-positive and Gramnegative bacteria. Clinical studies in the field of antibacterial PD are still relatively scarce, and much information is needed to enable relevant dosing strategies for all types of antibiotics against all common infections and microorganisms. In this review, the distinctive patterns of antimicrobial activity based on PD parameters are discussed. Various antibiotics and bacterial pathogens can be used as models to demonstrate the utility of PD parameters in predicting the in vivo efficacy of antimicrobial therapy. And finally, the use of computer modeling with Monte Carlo population simulations can further enhance the predictability of antimicrobial efficacy when using PD parameters.
\end{abstract}

Keywords: antibiotic, bacteria, pharmacodynamics, resistance

\section{INTRODUCTION}

Since the availability of antimicrobial chemotherapy, scientists and clinicians have sought and debated the most appropriate method to administer antibiotics with the purpose of optimizing the killing of microorganisms, while minimizing toxicity to the patient. The discipline of studying this interaction between antibiotics and their effects on pathogens is referred to antimicrobial pharmacodynamics (19). Some of the earliest documentation of antimicrobial pharmacodynamics dates back to studies with penicillin, where it was noted that maintaining concentrations via the use of continuous infusion improved the bactericidal activity compared with a bolus or 'discontinuous' dosing regimen (22). Today, these concepts are applied to currently available antibiotics and are a critical part of the development process for all new antimicrobial agents (14). During development, in vitro, in vivo animal, and human pharmacodynamic studies are employed to support dosage selection and for determination of susceptibility breakpoints (21). Unfortunately, the call for new antimicrobial agents with novel mechanisms of action and activity against certain multidrug resistant bacteria has been largely unmet by the pharmaceutical industry. As a result, pharmacodynamic study designs can be utilized to optimize the dosage regimens of already clinically available antibiotics and, in essence, "make good drugs better".

Increasing antimicrobial resistance within both Gram-positive and Gram-negative bacteria has further prompted a reevaluation of the selection of antimicrobial dosing regimens in terms of

*Corresponding Author. Mailing address: Departamento de Ciências Farmacêuticas - Disciplina Microbiologia Clínica - CCS - Universidade Federal da Paraiba - Campus Universitário da UFPB - João Pessoa PB - Brasil - CEP: 58051-970. Tel.: (83) 3216-7347. E-mail: lauro.santos@superig.com.br 
their pharmacokinetic and pharmacodynamic properties. In this review article, we summarize contemporary resistance data among the most common clinically relevant pathogens in Latin America, review pharmacodynamic concepts for currently available antimicrobials, and discuss various methods to optimize pharmacodynamics that may aid the reader in combating the resistance trends he or she face in clinical practice.

\section{Gram-Positive Resistance}

Among Gram-positive organisms, resistance within Staphylococcus aureus and coagulase negative staphylococci is most concerning. Methicillin resistance is the most clinically observed phenotype, and is also common worldwide. Rates of methicillin resistant S. aureus (MRSA) in South America are similar or slightly lower than North America, Europe, and Asia. Data from the SENTY Antimicrobial Surveillance Program conducted in Latin America during 2000 and 2001 found 38.6\% of $S$. aureus and $78.1 \%$ of coagulase negative staphylococci to be methicillin resistant (28). However, culture source is an important consideration as an earlier assessment from the same group found $46.2 \%$ MRSA among respiratory isolates between 1997 and 2000 (29). MRSA rates, obviously, can also differ from region to region and among institutions; rates were as high as $63 \%$ in some hospitals in Columbia (2). More recently, MRSA strains that are still susceptible to non- $\beta$-lactam antibiotics such as tetracyclines and trimethoprim-sulfamethoxazole, have been isolated with increasing frequency in the hospitalized population (18). These stains are similar to what is currently referred to as "community-acquired MRSA" in the United States, as they all produce a type IV staphylococcal cassette chromosome (SCC) mec gene (32).

Although vancomycin has been considered the antibiotic of choice for most MRSA infections, overuse of this compound has prompted development of vancomycin or glycopeptide intermediate resistant $S$. aureus (VISA or GISA) on many continents (Asia, Europe, North America), and the development of full vancomycin resistance (VRSA) in isolated cases in the United States $(13,48)$. The prevalence of these resistance phenotypes in Latin America is not currently well elucidated. Fortunately, antibiotics from other classes, such as linezolid, daptomycin, and tigecycline, are now available that have activity against MRSA, GISA, and VRSA, thereby providing treatment options for these resistant pathogens.

Increasing vancomycin use has also encouraged the development of vancomycin resistance among Enterococcus species, particularly within E. faecium. In Latin American countries, E faecalis is significantly more common than the faecium species (ratio of 17:1 compared with 3:1 to 5:1 in other parts of the world); furthermore, E. faecalis is rarely associated with vancomycin resistance. ${ }^{61}$ As a result, the overall prevalence of glycopeptide resistance in Latin America was only $4 \%$ during the 1997-2000 SENTRY Antimicrobial Surveillance Program.
More recent data from separate surveillance studies have observed vancomycin resistance rates in the range of $7 \%$ to $12 \%$ among all enterococci species globally $(17,68)$. While South American countries participated in these studies, the reports did not differentiate resistance rates by country or continent.

Streptococcus pneumoniae is a common cause of community-acquired infections in adults and pediatrics, most notably pneumonia, meningitis, and upper respiratory tract infections. Resistance to penicillin is the hallmark epidemiological measurement. In Latin American countries, penicillin non-susceptibility was approximately $30 \%$ during the 1997-2001 SENTRY study. ${ }^{12}$ However, high level penicillin resistance (MIC $\geq 2 \mu \mathrm{g} / \mathrm{ml}$ ) was only $11.9 \%$. Macrolide resistance (i.e., erythromycin) was also approximately $13 \%$ during that same time period; those isolates that displayed high-level resistance to penicillin were more likely to be non-susceptible to macrolides and trimethoprim-sulfamethoxazole. Subsequent years (up to 2003) from the SENTRY studies have demonstrated no increases in penicillin non-susceptibility or high-level resistance in these countries (33). Similar observations were seen in other surveillance studies $(11,56)$. Fluoroquinolone resistance, which has been increasing in Asia and Canada, remains less than $0.5 \%$ in Latin America. Nevertheless, emerging reports globally have indicated that as many of $29.9 \%$ of Streptococcus pneumoniae (including those that are fluoroquinolone susceptible) may harbor a first step mutation in ParC. ${ }^{9}$ Although, the clinical significance of this observation is not well known yet, reports of fluoroquinolone failures have been associated with the presence of this resistance mechanism $(5,38)$.

\section{Gram-negative Resistance}

Resistance among gram-negative bacteria, particularly Acinetobacter baumannii, Pseudomonas aeruginosa, and certain Enterobacteriaceae is of great concern in Latin American countries. During a recent review of global data collected during the Meropenem Yearly Susceptibility Test Information Collection (MYSTIC) Program, South America had the lowest susceptibility rates among tested $\beta$-lactams, fluoroquinolones, and aminoglycosides against Acinetobacter and P. aeruginosa compared with any other participating region of the world (79).

Acinetobacter baumannii and other Acinetobacter species are emerging opportunistic pathogens due to the ability for these organisms to produce numerous simultaneous resistance mechanisms. During the MYSTIC study (2002-2004), antibiotic susceptibilities were greatest for the carbapenems $(71.5 \%$ and $71.9 \%$ for meropenem and imipenem), followed distantly by gentamicin (48.0\%) and other antibiotic classes (79). Carbapenem resistance in one study, however, appeared to be highest among isolates from Argentina compared with other Latin America, thus it is apparent that clonal resistance that differs regionally is an important determinant of local resistance rates (77). In Brazil, Acinetobacter baumannii presented susceptibility rates 
to meropenem of $97.1 \%$ and $73 \%$ to tobramycin during the 2003 MYSTIC study (39). While the carbapenems (imipenem and meropenem) are still considered the antibiotics of choice for Acinetobacter infections, the occurrence of metallo- $\beta$ lactamases are increasing in frequency and cause high-level (MIC $>32 \mu \mathrm{g} / \mathrm{ml}$ ) resistance to these agents (66). They also efficiently hydrolyze other $\beta$-lactam antibiotics and are often resistant to fluoroquinolones and aminoglycosides via plasmid mediated resistance. These enzymes are fortunately still rare, but are more prevalent in certain Latin America countries compared with other regions of the world (66).

P. aeruginosa is one of the most common pathogenic Gramnegatives occurring in Latin America. Like Acinetobacter, it too, has the ability to develop numerous resistance mechanisms making it a problematic pathogen to treat. Antibiotic susceptibility during the 2002-2004 MYSTIC studies were 57.5\%, 56.9\%, 52.1\%, $47.3 \%, 45.6 \%$ and $44.4 \%$ for piperacillin/tazobactam, meropenem, imipenem, ceftazidime, ciprofloxacin, and gentamicin against 1159 P. aeruginosa from South America, respectively (79). These susceptibility rates were similar to those observed during the Brazilian analysis of MYSTIC (2003) as well as later years of the SENTY Antimicrobial Surveillance Program in Latin America (circa 2001) (7,39). In all of these analyses, the carbapenems, piperacillin/tazobactam, and the aminoglycosides (specifically, amikacin) had the greatest susceptibility rates. Nevertheless, resistance rates were still high for these compounds, and often the best agent had no better than $60-70 \%$ susceptibility against these strains. Like Acinetobacter, P. aeruginosa was also a culprit in the emerging production of carbapenemases and metallo- $\beta$-lactamases in Latin America (66).

As a result of such high levels of resistance among these non-fermenting Gram-negatives, therapeutic options based on microbiology alone are few. In such cases, polymixin, an old member of the polypeptide antibiotic class, may still serve some utility. Tested against 54,731 Gram-negative bacilli worldwide, polymixin resistance remained surprisingly low, even in Latin America (30). Resistance rates were only $1.1 \%$ and $1.7 \%$ against P. aeruginosa and Acinetobacter spp., respectively. However, susceptibility against other notable resistant non-fermenting Gram-negative bacteria was variable: Stenotrophomonas maltophilia (72.4\%), Burkholderia cepacia (11.8\%).

Among common Enterobacteriaceae, the most concerning resistance mechanisms include the production of Extended Spectrum $\beta$-lactamases (ESBLs) and derepression of the AmpC cephalosporinase. ESBL resistance is most notable within Klebsiella spp. and Escherichia coli, while AmpC resistance is frequent among Enterobacter spp. Although the ESBL rate for Klebsiella spp. has been steady over the last decade, it has been high. Between 1997-2000, 26.7\% to 49.6\% of Klebsiella spp. produced an ESBL; furthermore, most of the countries participating reported rates in the $40^{\text {th }}$ percentile $(29,67)$. Meanwhile, ESBL rates in E. coli have observed slight increases over that time period, from $4.7 \%$ in 1997 to $9.4 \%$ in 2000 (67). One study from Columbia observed similar ESBL rates for Klebsiella spp. and E. coli in 2002, although prevalence varied substantially among the 8 participating hospitals (81). These investigators also went on to characterize the ESBLs and found that $59 \%$ and $34 \%$ of Klebsiella pneumoniae and E. coli, respectively, produced multiple enzymes. These included TEM, SHV and most frequently, CTX-M enzymes. While Enterobacter spp. can also produce ESBLs, expression of the chromosomally mediated $\mathrm{AmpC}$ cephalosporinase is more common. Such pathogens display poor susceptibility to ceftazidime (68.4\%), as well as $\beta$-lactam/ $\beta$-lactamase inhibitors such as piperacillin/tazobactam (68\%) and ticarcillin/clavulanate $(56.5 \%)(67)$. However, cefepime remained very active against this pathogen in Latin America (91.5\% susceptible). In general, carbapenems retained activity for both these ESBL producing Enterobacteriaceae and those with derepressed AmpC.

Of particular concern is the increasing resistance of Gramnegatives to fluoroquinolone antibiotics. Ciprofloxacin susceptibility within Acinetobacter spp. and Pseudomonas are commonly less than 50\% and 70\% across Latin American countries. Resistance to other fluoroquinolones, such as levofloxacin and gatifloxacin, are even higher for these nonfermentors. Additionally, fluoroquinolone resistance within $E$. coli is rising (67). Susceptibility was approximately $85 \%$ in 2000 for these antibiotics; resistance is now over $20 \%$ in some countries $(2,67)$. Furthermore, in an analysis of various continents across the world that participated in both SENTRY and MYSTIC, Latin America was independently associated with ciprofloxacin non-susceptible $E$. coli and had the highest resistance rates compared with Northern Europe, Southern Europe, North America, and the Western Pacific (71). Fluoroquinolones, therefore, may not be a viable option for the treatment of many Gram-negative infections in the near future.

\section{Pharmacodynamic Principles}

In light of increasing resistance among Gram-positive and Gram-negative bacteria, opportunities exist to optimize antibiotic therapy against these organisms based on the knowledge of pharmacodynamics, i.e., how the drugs and bugs interact. First, it is imperative to realize some consistencies among the pharmacodynamic relationships discussed below. Foremost, it is the free or unbound antibiotic that is responsible for antibacterial activity (19). Drug that is bound to human proteins, routinely albumin, cannot effectively bind to their site of action on the bacteria and induce their antimicrobial activity. In cases where an antibiotic has low protein binding, the total drug concentrations are a reasonable indicator of exposure, but in cases of highly bound drugs, a correction factor should be utilized. Second, antibiotic concentrations in the human body are often referenced to the blood because it is easiest to determine concentrations at this site. However, it should be 
emphasized that the antibiotic must get to the site of the infection, and therefore tissue penetration should be considered. In some cases, antibiotics do not penetrate completely to the site of infection ( $\beta$-lactam penetration into the epithelial lining fluid [ELF] of the lung, or any antibiotic into the cerebral spinal fluid), thus the knowledge of blood concentrations only may lead to an overestimation of the actual tissue concentrations. In contrast, other antibiotics may accumulate at the site of infection and therefore concentrations are several fold higher than they are in blood (e.g., macrolides, ketolides and fluoroquinolones in the ELF, or $\beta$-lactams in the urine).

Antimicrobial killing is dependent on both the concentration of drug in relation to the MIC and the time that this exposure is maintained (Fig. 1) (14,19). When the effect of concentration predominates over that of time, the antimicrobial is said to be concentration-dependent and bactericidal effects are associated with an optimal free drug maximum concentration to MIC ratio $\left(f \mathrm{C}_{\max } / \mathrm{MIC}\right)$. When the effect of time is greater, the antibiotic displays time-dependent antibiotic activity, and bacterial outcomes are associated with free drug concentrations above the MIC for a defined portion of the dosing interval, or time above the MIC ( $f \mathrm{~T}>\mathrm{MIC})(78)$. A summary of currently available antibiotics and their respective pharmacodynamic categories is listed in Table 1.

At standard doses, concentration-dependent antimicrobials include the aminoglycosides, fluoroquinolones, daptomycin, metronidazole and colistin $(14,17,47,70)$. The goal when dosing concentration-dependent antimicrobials is to achieve a $\mathrm{C}_{\max } / \mathrm{MIC}$ of approximately 10 to $12(59,60,64)$. Thus, a pharmacodynamic approach to administering the aminoglycosides would be to give

Table 1. Summary of antibiotics that display concentration-dependent or time-dependent killing characteristic and the requisite pharmacodynamic exposure.

\begin{tabular}{|c|c|c|}
\hline Antibiotic Class - Antibiotic & Killing Characteristic & Pharmacodynamic Parameter* \\
\hline $\begin{array}{l}\beta \text {-lactams } \\
\quad \text { carbapenems (ertapenem, imipenem, meropen } \\
\text { cephalosporins (e.g., ceftazidime, cefepime) } \\
\text { penicillins (e.g., penicillin, oxacillin, } \\
\text { piperacillin/tazobactam) }\end{array}$ & Time Dependent & $\begin{array}{l}40 \% f \mathrm{~T}>\mathrm{MIC} \text { (bactericidal activity, Gram-negatives) } \\
40 \%-70 \% \text { T }>\text { MIC (bactericidal activity, Gram-negatives) } \\
50 \% \text { f } \mathrm{T}>\mathrm{MIC} \text { (bactericidal activity, Gram-negatives) }\end{array}$ \\
\hline $\begin{array}{l}\text { Fluoroquinolones } \\
\quad \text { ciprofloxacin, levofloxacin, moxifloxacin }\end{array}$ & Concentration Dependent & $\begin{array}{l}\text { AUC/MIC }>125 \text { (Gram-negatives) } \\
\text { fAUC/MIC }>30-50 \text { (Gram-positives) }\end{array}$ \\
\hline $\begin{array}{r}\text { Glycopeptides } \\
\text { vancomycin }\end{array}$ & Time Dependent & AUC/MIC > 345 \\
\hline $\begin{array}{l}\text { Ketolides } \\
\text { telithromycin }\end{array}$ & Concentration Dependent & AUC/MIC $\geq 3.375$ \\
\hline $\begin{array}{l}\text { Lipopeptides } \\
\text { daptomycin }\end{array}$ & Concentration Dependent & $\begin{array}{l}\text { fAUC/MIC } 12-36 \text { (Staphylococcus aureus) } \\
\text { fAUC/MIC 5-13 (Enterococcus spp.) }\end{array}$ \\
\hline $\begin{array}{l}\text { Macrolides } \\
\text { azithromycin } \\
\text { clarithromycin }\end{array}$ & Time Dependent & $\begin{array}{l}\text { AUC/MIC > } 254 \\
40 \%-50 \% \text { T }>\text { MIC }\end{array}$ \\
\hline $\begin{array}{l}\text { Nitroimidazoles } \\
\text { metronidazole }\end{array}$ & Concentration Dependent & AUC/MIC > 70 (Bacteroides fragilis) \\
\hline
\end{tabular}

* Exposures are total drug unless otherwise noted 


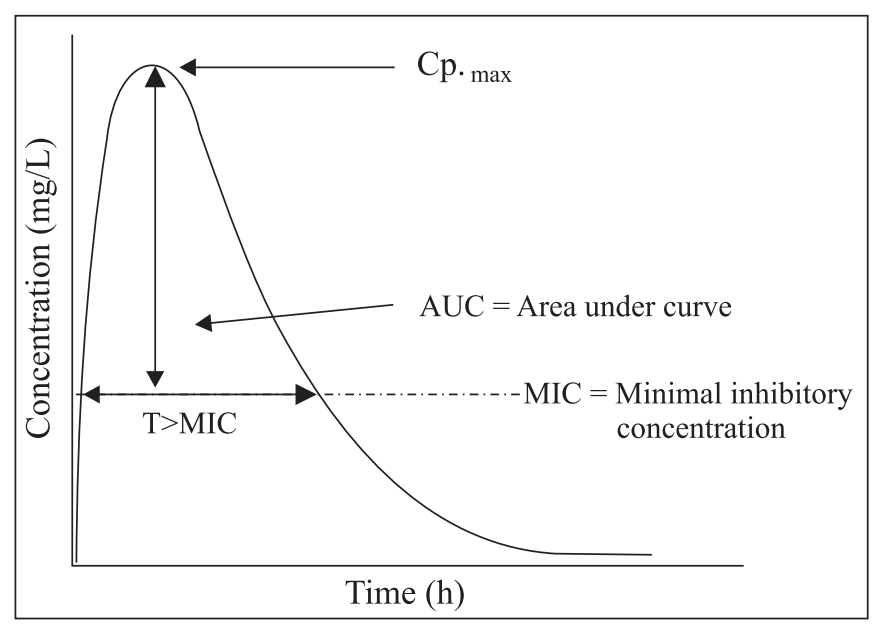

Figure 1. Depiction of pharmacodynamic parameters over a concentration time profile

a very large dose once daily in order to maximize the $\mathrm{C}_{\max } / \mathrm{MIC}$ (26). While fluoroquinolones are concentration-dependent antimicrobials, the maximum dose that can be given is limited by dose-related toxicity, thus a $\mathrm{C}_{\max } / \mathrm{MIC}$ of 10 to 12 cannot be achieved for many pathogens and time must be considered to maximize response. Therefore, in many pharmacodynamic studies, the bactericidal effect has been correlated with the area under the curve (AUC) to MIC (45). Against Gram-negative bacteria an AUC/MIC $\geq 125$ is required for maximal effect, while Gram-positive bacteria, such as Streptococcus pneumoniae, require an AUC/ $\mathrm{MIC} \geq 30$ (83).

Unlike many other classes of antimicrobials, the fluoroquinolone and aminoglycoside pharmacodynamic breakpoints have been validated in human trials, as opposed to only in vitro and in vivo animal studies. This was done with the aminoglycosides during the 1980's and more recently with fluoroquinolones against both Gram-negative and Grampositive pathogens $(3,20,25,57,60,64)$. In a study of 74 patients receiving ciprofloxacin for serious nosocomial infections, an AUC/MIC below 125 was associated with a lower probability of clinical and microbiologic response (25). Additionally, an AUC/ MIC above 125 and above 250 were significantly associated with shorter median times to eradication (AUC/MIC $<125: 32$ days, 125-250: 6.6 days, $>250$ : 1.9 days, $\mathrm{P}<0.005)$. However, it is important to acknowledge that the majority of patients included were infected with Gram-negative bacteria and that the authors did not consider the protein binding of ciprofloxacin in their analysis. In another study, a levofloxacin total drug AUC/MIC exposure greater than or equal to 87 was prospectively determined to be an important factor in predicting eradication in 47 patients with nosocomial pneumonia (20). This study included both Gram-positive and Gram-negative pathogens, as well as the use of combination therapy for Pseudomonas aeruginosa. These variables along with slightly different methodologies, including consideration of protein binding or not, may partially explain why the pharmacodynamic breakpoints among these studies do not agree.

In a separate study evaluating gatifloxacin and levofloxacin pharmacodynamics against S. pneumoniae, Ambrose and colleagues found that a free drug AUC/MIC greater than 33.7 was a significant predictor of clinical and microbiological response in patients with lower respiratory tract infections (3). While providing important information regarding the in vivo pharmacodynamic profiling for these agents, this study did not appear to include isolates with varying fluoroquinolone genotypic resistance profiles such as $\operatorname{ParC}$. Moreover, recently derived in vitro pharmacodynamic data with isolates containing these genotypic mutations have suggested that considerably higher exposures (i.e., AUC/MIC) are required to produce bactericidal outcomes and prevent the emergence of further resistance $(1,24)$. Similar observations have been documented against $P$. aeruginosa, suggesting that an AUC/MIC of 125 may not be great enough to prevent resistance $(34,72)$.

Time-dependent antimicrobials include $\beta$-lactams, vancomycin, some macrolides, tigecycline, and clindamycin. In general, $\beta$-lactam antibiotics require $f \mathrm{~T}>\mathrm{MIC}$ for $50 \%$ of the dosing interval; however, exposure can vary by the specific $\beta$ lactam class. For instance, while the penicillins commonly require approximately $50 \% f \mathrm{~T}>\mathrm{MIC}$ for bactericidal effects, discordance among exposures for the cephalosporins has been reported with a requirement between $50 \%$ and $70 \% f \mathrm{~T}>\mathrm{MIC}$ for bactericidal activity (78). Additionally, in vivo animal studies with the fourth generation cephalosporin, cefepime, have demonstrated bactericidal effects at free drug exposures as low as $40 \% f \mathrm{~T}>\mathrm{MIC}$ for Escherichia coli irrespective of the production of extended-spectrum $\beta$-lactamases (ESBLs) (53). The carbapenem class (i.e., imipenem, meropenem, ertapenem) of antibiotics are generally thought to require less $\mathrm{T}>\mathrm{MIC}$ because of their post-antimicrobial effect against Gram-negative bacteria and their high affinity for penicillin binding proteins (54). Bacteriostatic and bactericidal effects are observed at $20 \%$ and $40 \% f \mathrm{~T}>\mathrm{MIC}$, respectively.

In contrast to the aminoglycosides and fluoroquinolones, little data in humans are available to directly validate these pharmacodynamic endpoints for $\beta$-lactams. Instead, numerous studies have linked clinical response with MIC; a detailed review of these studies has been published (78). In a separate review, a quantitative relationship between time above the $\mathrm{MIC}_{90}$ in serum and bacteriologic success for a variety of $\beta$-lactams (penicillins and cephalosporins) in the treatment of otitis media and acute maxillary sinusitis was demonstrated (16). The authors demonstrated that bacteriologic success was greatest when the T>MIC was at least $50 \%$ of the dosing interval. More recently, the pharmacodynamics of cefepime were determined 
in 20 patients with $P$. aeruginosa infections (74). These investigators observed a strong link between microbiological success and T $>$ MIC. Success was $89 \%$ when T $>$ MIC was $100 \%$ compared with $0 \%$ when $\mathrm{T}>\mathrm{MIC}$ was less than $100 \%, \mathrm{p}=0.032$. A minimum concentration $\left(\mathrm{C}_{\min }\right) / \mathrm{MIC}>4.3$, however, was independently predictive of response. A similar analysis of 101 adults with lower respiratory tract infections receiving meropenem demonstrated that while all pharmacodynamic parameters could be linked to response, the $f \mathrm{C}_{\mathrm{min}} / \mathrm{MIC}$ was most predictive; a ratio greater than 5 was required to predict microbiological eradication (46). Although these were small studies and had their limitations, the data suggest that higher pharmacodynamic targets than previously documented from in vitro and animal studies may be needed in the clinical setting.

Although vancomycin success for Gram-positive infections has historically been thought to be associated with $\mathrm{T}>\mathrm{MIC}$, data actually suggest that the AUC/MIC ratio best predicts outcomes for this time-dependent antibiotic (65). Studies in patients with pulmonary infections caused by $S$. aureus observed that vancomycin response was associated with a total drug AUC/MIC > 345, and microbiological eradication was associated with an AUC/MIC > $400(57,58)$. Assuming about $50 \%$ protein binding, these total drug targets are similar to the $f$ AUC/MIC targets found in the original in vivo murine thigh infection models required for a static effect (65). Alternative supportive data are provided by studies suggesting that outcomes for $S$. aureus bacteremia were very low when the MIC was $>1 \mu \mathrm{g} / \mathrm{ml}$; at this MIC, the standard vancomycin dose (1g q12h) does not attain these AUC/MIC exposures in patients with reasonable renal function (69). Pharmacodynamic data for teicoplanin, another glycopeptide, is not available yet, but should be similar to vancomycin targets.

As newer antibiotics become clinically available, the determination of pharmacodynamic endpoints for these agents is also conducted. When the pharmacodynamics of the novel ketolide, telithromycin, was examined in murine infection models, it was noted to display concentration-dependent killing, with the free AUC/MIC being most predictive of bacterial load reduction (76). This finding is in discordance with older macrolides, which are better described as time-dependent killing antibiotics (37). More recently, telithromycin pharmacodynamics were examined in 115 patients with community-acquired pneumonia caused by extracellular pathogens, most of which were Haemophilus influenzae and S. pneumoniae (50). An AUC/ MIC $\geq 3.375$ was associated $90.8 \%$ positive predictive value for eradication, while values below this breakpoint where associated with $23.5 \%$ negative predictive value. This means that the determined breakpoint was highly sensitive for identifying eradication, but not specific for it, so that a patient not obtaining an AUC/MIC of 3.375 would not necessarily always fail therapy, but might be more likely to do so. Linezolid is the first in class oxazolidinone. The pharmacodynamics of this agent have been assess in a murine thigh infection model, and a total AUC/ MIC of 39 to 167 (mean $=83$ ) was required to produce a static effect against $S$. aureus, including a methicillin resistant strain (6). Half the exposure was required against S. pneumoniae. Daptomycin pharmacodynamics were concentrationdependent in murine infection models against $S$. aureus and enterococci; a free AUC/MIC ratio of 12 to 36 and 5 to 13, respectively, were associated with static effects $(17,51)$. Finally, the pharmacodynamics of tigecycline, a novel glycylcycline antibiotic derived from minocycline were analyzed in patients with complicated skin and skin structure infections and complicated intra-abdominal infections. Tigecycline displays time-dependent activity, and a total AUC/MIC $\geq 6.96$ and $\geq 12.5$ - 17.9 for Gram-negative and Gram-positive bacteria, respectively, was predictive of successful clinical responses $(55,63,80)$.

\section{Optimizing Pharmacodynamics}

New antibiotics are needed to combat the emerging resistance in Latin American countries. While novel Grampositive antibiotics have been introduced that have activity against MRSA, VRE, and penicillin-resistant S. pneumoniae, antibiotics with activity against multidrug-resistant $A$ cinetobacter spp. and P. aeruginosa are many years from clinical development. As a result, we must look to our currently available antibiotic armamentarium for clinical use against these organisms. Pharmacodynamic concepts can be utilized to develop strategies to optimize the dosing of these antibiotics, in many cases, without sacrificing patient safety.

Aminoglycosides (tobramycin, gentamicin, and amikacin) are an important therapeutic option for non-fermenting Gram negative infections, especially in combination with other antibiotic classes. Because these antibiotics are concentration-dependent and the $\mathrm{C}_{\max } / \mathrm{MIC}$ ratio is associated with positive outcomes, increasing the administered dose of these drugs should be considered. Moreover, because higher concentrations are obtained, the dosing interval can be extended to prevent aminoglycoside accumulation and associated nephro- and ototoxicity. This dosing strategy has been termed Once Daily or Extended Interval Aminoglycoside Dosing. Numerous data support the use of extended interval aminoglycosides, and some reports have suggested less toxicity with this regimen (26). Individualized pharmacokinetic monitoring has been proposed as the most accurate method to achieve the target $\mathrm{C}_{\max }$ /MIC of 10 to $12(35,82)$. However, one must consider the cost of multiple drug samples, the potential for impractical dosing schedules, the requirement for a significant understanding of pharmacokinetic principles by the clinician, and the expertise and time associated with using pharmacokinetic computer software to calculate kinetic parameters. Moreover, the denominator in the $\mathrm{C}_{\max } / \mathrm{MIC}$ ratio is seldom available to the practicing clinician, thus the economic benefit of potentially administering lower doses for bacteria with a lower aminoglycoside MIC is rarely realized. This individualized 
approach, however, is the most appropriate method for administering the agent to patients with unusual pharmacokinetics, such as pregnant women, burn patients, or patients with ascites, etc. Another approach to extended-interval aminoglycoside administration has been through the use of population kinetics and institution specific dosing nomograms $(4,31,62)$.

The dose of an aminoglycoside should be based on the MIC of the causative pathogen, when available. If using a nomogram, the ideal dose should be one that is based on the aminoglycoside $\mathrm{MIC}_{90}$ for the most common pathogen targeted at that specific institution (e.g., P. aeruginosa). Some nomograms have suggested doses of $5 \mathrm{mg} / \mathrm{kg}$ instead of $7 \mathrm{mg} / \mathrm{kg}$ once daily. In many instances a dose of $5 \mathrm{mg} / \mathrm{kg}$ is more than adequate to achieve a $\mathrm{C}_{\max } / \mathrm{MIC}$ ratio of 10 to 12 . In other cases, a dose higher than $7 \mathrm{mg} / \mathrm{kg}$ may be necessary if the MIC is greater than $2 \mu \mathrm{g} / \mathrm{mL}$. Continued monitoring of MIC distribution changes is necessary to assure appropriate use of nomogram dosing.

Due to their activity against many multidrug-resistant nonfermenting Gram-negative rods, colistin (polymyxin E) or polymyxin B remain potential treatment options (23). Unfortunately, the pharmacodynamics of these agents are not well established and clinicians are not likely using appropriate dosing based on pharmacodynamic concepts; moreover, one must consider the potential for nephrotoxicity and peripheral neuropathy with this antibiotics. One in vitro study that linked AUC/MIC to the development of resistance observed that a dose 8 times greater than the standard $2.5 \mathrm{mg} / \mathrm{kg}$ dose was required to maintain bactericidal activity at 24 hours (1). They suggested further studies with higher, but less frequent polymyxin B dosing, similarly to what is done with the aminoglycosides.

Manipulation of the dosage of $\beta$-lactams offers among the broadest spectrum of possibilities for optimizing pharmacodynamics. This is further supported by the safety of these compounds at higher doses, as well as their popularity as antibiotic workhorses in many hospitals. Since the $\beta$-lactams are time-dependent killing agents, maximizing the $f \mathrm{~T}>\mathrm{MIC}$ is necessary for optimal bacterial load reduction. Accordingly, numerous strategies such as prolonging the infusion time over several hours, or administering the antibiotics as a continuous infusion over the entire day, have been advocated $(15,54)$. Both prolonged and continuous infusion dosing concepts require less antibiotic to achieve similar exposures to standard intermittent infusions and thus may provide an economic benefit; however, it is the ability to use high doses along with these dosing strategies to pursue treatment of less susceptible pathogens $(10,37,43,49)$.

Numerous $\beta$-lactams have been studied as continuous infusions, the majority of which would otherwise require numerous daily dosing because of short serum half-lives, such as piperacillin/tazobactam, ceftazidime, cefepime, oxacillin, and nafcillin. The only caveats to continuous infusion are the requirement of room temperature stability for the 24 hours and dedicated line access. In the case of poor stability, continuous infusion can still be conducted if the bag is changed within the required time frame or if the infusion bag is surrounded by freezer packs to maintain stability (54). Alternatively, the prolonged infusion strategy may be adopted. This concept involves infusing the $\beta$-lactam for only a few hours (e.g., 3. to 4 hours) on a standard every 6 to 8 hour schedule. The majority of data with prolonged infusion have been conducted with carbapenems due to their poor stability at room temperature; however, logistically, this can be applied to any $\beta$-lactam. Data with piperacillin/tazobactam and cefepime are available $(49,73)$.

Unfortunately, unlike aminoglycosides and vancomycin, most hospitals do not have the resources to conduct $\beta$-lactam concentration monitoring; therefore, it is more difficult to individualize dosing strategies for these antibiotics. In the absence of concentration data, population pharmacokinetic models and Monte Carlo simulation can be utilized to estimate the likelihood of different dosage regimens achieving the requisite pharmacodynamic target (8). Monte Carlo simulation is a stochastic model that considers the variability in patient pharmacokinetic parameters as well as the likelihood of infection with an organism with a specific MIC (44). Combined with local or national surveillance MIC data, these models can assist in choosing among antibiotic regimens empirically, and determining optimal dosage regimens to employ against less susceptible bacteria $(42,44)$. This technique was utilized to assess differing antibiotic regimens against Gram-negative bacteria collected from the MYSTIC Program in South America (41). The simulations suggested that meropenem and imipenem had the greatest likelihood of achieving bactericidal exposure against the non-fermenting Gram-negative bacteria, although neither regimen attained high probabilities. Thus, combination therapy was advocated. Additionally, the simulations pointed to discrepancies between susceptibility and pharmacodynamic attainment against $P$. aeruginosa, specifically for piperacillin/ tazobactam $4.5 \mathrm{~g} q 8 \mathrm{~h}$ and ciprofloxacin $400 \mathrm{mg} \mathrm{q} 12 \mathrm{~h}$. Whereas susceptibility was approximately $67 \%$ and $55 \%$, respectively, target attainment was only $26 \%$ and $33 \%$, suggesting that standard dosages for these antibiotics may be too low for even susceptible bacteria.

If local susceptibility data are known, dosing strategies such as prolonged or continuous infusion can be implemented to increase the likelihood of target attainment against less susceptible bacteria. An assessment of the bacteria implicated in consecutive infections in one hospital's intensive care unit in Brazil demonstrated that standard dosing regimens might not be ideal empirically due to high resistance rates (40). $P$. aeruginosa was the most commonly isolated organism, and a high dose, prolonged infusion regimen of meropenem $(2 \mathrm{~g} \mathrm{q} 8 \mathrm{~h}$ as a 3 hour infusion) achieved $88 \%$ likelihood, while the standard $1 \mathrm{~g} \mathrm{q} 8 \mathrm{~h}$ (30 minute infusion) regimen achieved only $80.7 \%$. This 
pharmacodynamically optimized regimen for meropenem can achieve $\geq 40 \% f \mathrm{~T}>\mathrm{MIC}$ against organism considered meropenem intermediate (MIC $=8 \mu \mathrm{g} / \mathrm{ml}$ ) and those considered resistant $(\mathrm{MIC}=16 \mu \mathrm{g} / \mathrm{ml})(42,73)$. Similarly, a high dose prolonged infusion of cefepime (2g q8h as a 3-4 hour infusion) can achieve $\geq 50 \% f \mathrm{~T}>\mathrm{MIC}$ against organisms considered cefepime intermediate $(\mathrm{MIC}=16 \mu \mathrm{g} / \mathrm{ml})$ and resistant $(\mathrm{MIC}=32 \mathrm{mg} / \mathrm{ml})$ $(52,73)$. In the unfortunate case that organisms with these MIC values exist in one's hospital population, these optimized dosing regimens should be advocated empirically until susceptibility data are available.

\section{CONCLUSIONS}

Antimicrobial resistance among Gram-positive and Gramnegative bacteria in Latin American countries is increasing. Since few novel antibiotics are near market entrance, specifically against Gram-negatives such as P. aeruginosa and Acinetobacter spp., we must optimize the dosing of currently available agents. Pharmacodynamic studies in essentially all antibiotics are available demonstrating relationships between concentration, MIC, and microbiological effects. Furthermore, quantitative targets can help clinicians and researchers design dosing regimens that have a high likelihood of obtaining requisite exposures for use in daily clinical practice. In some instances, novel administration strategies including high-dose extended intervals for aminoglycosides and prolonged or continuous infusion for $\beta$-lactams will be required to optimize antibiotic pharmacodynamics against these less susceptible pathogens.

\section{RESUMO}

\section{Utilização de princípios de farmacocinética e farmacodinâmica na otimização do tratamento antimicrobiano com relação à resistência emergente}

A eficácia antimicrobiana in vivo não pode ser definida exclusivamente pela atividade de um antibiótico determinada por um teste de sensibilidade in vitro. O conhecimento da farmacocinética e farmacodinâmica dos antimicrobianos, assim como de todos os fenômenos que ocorrem entre agentes antimicrobianos e microrganismos é fundamental na interpretação de alguns resultados. Os parâmetros farmacodinâmicos (PD) mais frequentemente usados nos estudos do efeito dos antibióticos incluem os seguintes relacionamentos: a concentração livre máxima $\left(f \mathrm{C}_{\max }\right)$ com relação à concentração inibitória mínima (CIM), a área livre sob a curva ( $(A U C / C I M)$ e a duração do tempo em que a concentração livre excede a CIM ( $f \mathrm{~T}>\mathrm{CIM}$ ). A utilização dos dados conhecidos de farmacocinética/farmacodinâmica devem ajudar a otimizar o resultado dos tratamentos adotados, especialmente com relação à resistência emergente entre as bactérias Gram-positivas e Gram-negativas. Os estudos clínicos no campo da farmacodinâmica dos antimicrobianos ainda são relativamente escassos, e muita informação é necessária para permitir estratégias de dosagem relevantes para todos os tipos de antibióticos contra a todas as infecções e microorganismos comuns. Nesta revisão, os padrões distintos da atividade antimicrobiana baseado em parâmetros de farmacodinâmica são discutidos. Vários antibióticos e patógenos bacterianos podem ser usados como modelos para demonstrar a utilidade de parâmetros de farmacodinâmica em predizer a eficácia in vivo da terapia antimicrobiana. E finalmente, o uso da modelagem computadorizada utilizando a simulação de Monte Carlo em determinadas populações podem realçar ainda mais o valor preditivo e a eficácia antimicrobiana quando se utilizam parâmetros de farmacodinâmica nas interpretações.

Palavras chave: antibiótico, bactérias, farmacodinâmica, resistência

\section{REFERENCES}

1. Allen, G.P.; Kaatz, G.W.; Rybak, M.J. (2003). Activities of mutant prevention concentration-targeted moxifloxacin and levofloxacin against Streptococcus pneumoniae in an in vitro pharmacodynamic model. Antimicrob. Agents Chemother, 47, 2606-2614.

2. Alvarez, C.; Cortes, J.; Arango, A.; Correa, C.; Leal, A. (2006). Antimicrobial resistance in intensive care units in Bogota, Colombia, 2001-2003. Rev. Salud Publica (Bogota), 8 (Suppl 1), 86-101.

3. Ambrose, P.G.; Grasela, D.M.; Grasela, T.H.; Passarell, J.; Mayer, H.B.; Pierce, P.F. (2001). Pharmacodynamics of fluoroquinolones against Streptococcus pneumoniae in patients with communityacquired respiratory tract infections. Antimicrob. Agents Chemother, $45,2793-2797$

4. Anaizi, N. (1997). Once daily dosing of aminoglycosides: a consensus document. Int. J. Clin. Pharmacol. Ther., 35, 223-226.

5. Anderson, K.B.; Tan, J.S.; File, T.M. DiPersio, J.R.; Willey, B.M.; Low, D.E. (2003). Emergence of levofloxacin-resistant pneumococci in immunocompromised adults after therapy for community-acquired pneumonia. Clin. Infect. Dis., 37, 376-81.

6. Andes, D.; van Ogtrop, M.L.; Peng, J.; Craig, W.A. (2002). In vivo pharmacodynamics of a new oxazolidinone (linezolid). Antimicrob. Agents Chemother., 46, 3484-3489.

7. Andrade, S.S.; Jones, R.N.; Gales, A.C.; Sader, H.S. (2003). Increasing prevalence of antimicrobial resistance among Pseudomonas aeruginosa isolates in Latin American medical centres: 5 year report of the SENTRY Antimicrobial Surveillance Program (1997-2001). J. Antimicrob. Chemother, 52, 140-141.

8. Bradley, J.S.; Dudley, M.N.; Drusano, G.L. (2003). Predicting efficacy of anti-infectives with pharmacodynamics and Monte Carlo simulation. Pediatr. Infect. Dis. J., 22, 982-992.

9. Brueggemann, A.B.; Coffman, S.L.; Rhomberg, P.; Huynh, H.; Almer, L.; Nilius, A.; Flamm, R.; Doern, G.V. (2002). Fluoroquinolone resistance in Streptococcus pneumoniae in United States since 19941995. Antimicrob. Agents Chemother, 46, 680-688.

10. Buck, C.; Bertram, N.; Ackermann, T.; Sauerbruch, T.; Derendorf, H.; Paar, W.D. (2005). Pharmacokinetics of piperacillin-tazobactam: intermittent dosing versus continuous infusion. Int. J. Antimicrob. Agents, 25, 62-67.

11. Camargos, P.; Fischer, G.B.; Mocelin, H.; Dias, C.; Ruvinsky, R. (2006). Penicillin resistance and serotyping of Streptococcus pneumoniae in Latin America. Paediatr. Respir. Rev., 7, 209-214. 
12. Castanheira, M.; Gales, A.C.; Mendes, R.E.; Jones, R.N.; Sader, H.S. (2004). Antimicrobial susceptibility of Streptococcus pneumoniae in Latin America: results from five years of the SENTRY Antimicrobial Surveillance Program. Clin. Microbiol. Infect., 10, 645-651.

13. Cosgrove, S.E.; Carroll, K.C.; Perl, T.M. (2004). Staphylococcus aureus with reduced susceptibility to vancomycin. Clin. Infect. Dis., 39, 539-545.

14. Craig, W.A. (1998). Pharmacokinetics/pharmacodynamic parameters: rationale for antibacterial dosing of mice and men. Clin. Infect. Dis., 26, $1-10$.

15. Craig, W.A.; Ebert, S.C. (1992). Continuous infusion of $\beta$-lactam antibiotics. Antimicrob. Agents Chemother., 36, 2577-2583.

16. Dagan, R.; Klugman, K.P.; Craig, W.A.; Baquero, F. (2001). Evidence to support the rationale that bacterial eradication in respiratory tract infection is an important aim of antimicrobial therapy. $J$. Antimicrob. Chemother., 47, 129-140.

17. Dandekar, P.K.; Tessier, P.R.; Williams, P.; Nightingale, C.H.; Nicolau, D.P. (2003). Pharmacodynamic profile of daptomycin against Enterococcus species and methicillin-resistant Staphylococcus aureus in a murine thigh infection model. J. Antimicrob. Chemother, 52, 405-411.

18. De A. Trindade, P.; Pacheco, R.L.; Costa, S.F.; Rossi, F.; Barone, A.A.; Mamizuka, E.M.; Levin, A.S. (2005). Prevalence of SCCmec type IV in nosocomial bloodstream isolates of methicillin-resistant Staphylococcus aureus. J. Clin. Microbiol., 43, 3435-3437.

19. Drusano, G.L. (2004). Antimicrobial pharmacodynamics: critical interactions of 'bug and drug'. Nat. Rev. Microbiol., 2, 289-300.

20. Drusano, G.L.; Preston, S.L.; Fowler, C.; Corrado, M.; Weisinger, B.; Kahn, J. (2004). Relationship between fluoroquinolone area under the curve: minimum inhibitory concentration ratio and the probability of eradication of the infecting pathogen, in patients with nosocomial pneumonia. J. Infect. Dis., 189, 1590-1597.

21. Dudley, M.N.; Ambrose, P.G. (2000). Pharmacodynamics in the study of drug resistance and establishing in vitro susceptibility breakpoints: ready for prime time. Curr. Opin. Microbiol., 3, 515-521.

22. Eagle, H.; Fleischman, R.; Levy, M. (1953). "Continuous" vs. "discontinuous" therapy with penicillin: the effect of the interval between injections on therapeutic efficacy. N. Eng. J. Med., 248, 481-488.

23. Falagas, M.E.; Kasiakou, S.K.; Kofterisis, D.P.; Roditakis, G.; Samonis, G. (2006). Effectiveness and nephrotoxicity of intravenous colistin for treatment of patients with infections due to polymyxin-onlysusceptible (POS) gram-negative bacteria. Eur. J. Clin. Microbiol. Infect. Dis., 25, 596-599.

24. Florea, N.R.; Tessier, P.R.; Zhang, C.; Nightingale, C.H.; Nicolau, D.P. (2004). Pharmacodynamics of moxifloxacin and levofloxacin at simulated epithelial lining fluid drug concentrations against Streptococcus pneumoniae. Antimicrob. Agents Chemother., 48, $1215-1221$

25. Forrest, A.; Nix, D.E.; Ballow, C.H.; Goss, T.F.; Birmingham, M.C.; Schentag, J.J. (1993). Pharmacodynamics of intravenous ciprofloxacin in seriously ill patients. Antimicrob. Agents Chemother., 37, 10731081 .

26. Freeman, C.D.; Nicolau, D.P.; Belliveau, P.P.; Nightingale, C.H. (1997). Once-daily dosing of aminoglycosides: review and recommendations for clinical practice. J. Antimicrob. Chemother., 39, 677-686.

27. Fritsche, T.R.; Sader, H.S.; Stilwell, M.G.; Dowzicky, M.J.; Jones, R.N. (2005). Potency and spectrum of tigecycline tested against an international collection of bacterial pathogens associated with skin and soft tissue infections (2000-2004). Diagn. Microbiol. Infect. Dis., 52, 195-201.

28. Gales, A.C.; Andrade, S.S.; Sader, H.S.; Jones, R.N. (2004). Activity of mupirocin and 14 additional antibiotics against staphylococci isolated from Latin American hospitals: report from the SENTRY antimicrobial surveillance program. J. Chemother., 16, 323-328.
29. Gales, A.C.; Sader, H.S.; Jones, R.N. (2002). Respiratory tract pathogens isolated from patients hospitalized with suspected pneumonia in Latin America: frequency of occurrence and antimicrobial susceptibility profile: results from the SENTRY Antimicrobial Surveillance Program (1997-2000). Diagn. Microbiol. Infect. Dis., 44, 301-311.

30. Gales, A.C.; Jones, R.N.; Sader, H.S. (2006). Global assessment of the antimicrobial activity of polymixin B against 54,731 clinical isolates of Gram-negative bacilli: report from the SENTRY antimicrobial surveillance programme (2001-2004). Clin. Microbiol. Infect., 12, 315-321.

31. Gilbert, D.N.; Moellering, R.C.; Sande, M.A. (eds). (2001). The Sanford guide to antimicrobial therapy 2001, 31 $1^{\text {st }} \mathrm{ed}$. Hyde Park, VT: Antimicrobial Therapy, Inc.

32. Herold, M.C.; Hulten, K.G.; Palazzi, D.L.; Campbell, J.R.; Baker, C.J. (1998). Community-acquired methicillin-resistant Staphylococcus aureus in children with no identified predisposing risk. JAMA, 279 593-598.

33. Johnson, D.M.; Stilwell, M.G.; Fritsche, T.R.; Jones, R.N. (2006) Emergence of multidrug-resistant Streptococcus pneumoniae: report from the SENTRY Antimicrobial Surveillance Program (1999-2003) Diagn. Microbiol. Infect. Dis., 56, 69-74.

34. Jumbe, N.; Louie, A.; Leary, R.; Liu, W.; Deziel, M.R.; Tam, V.H.; Bachhawat, R.; Freeman, C.; Kahn, J.B., Bush, K.; Dudley, M.N.; Miller, M.H.; Drusano, G.L. (2003). Application of a mathematical model to prevent in vivo amplification of antibiotic-resistant bacterial populations during therapy. J. Clin. Invest., 112, 275-285.

35. Kashuba, A.D.M.; Bertino, J.S.; Nafziger, A.N. (1998). Dosing of aminoglycosides to rapidly attain pharmacodynamic goals and hasten therapeutic response by using individualized pharmacokinetic monitoring of patients with pneumonia caused by gram-negative organisms. Antimicrob. Agents Chemother., 42, 1842-1844.

36. Kasiakou, S.K.; Lawrence, K.R.; Choulis, N.; Falagas, M.E. (2005). Continuous versus intermittent intravenous administration of antibacterials with time-dependent action: a systematic review of pharmacokinetic and pharmacodynamic parameters. Drugs, 65, 2499-2511.

37. Kays, M.B.; Denys, G.A. (2001). In vitro activity and pharmacodynamics of azithromycin and clarithromycin against Streptococcus pneumoniae based on serum and intrapulmonary pharmacokinetics. Clin. Ther., 23, 413-424.

38. Kays, M.B.; Smith, D.W.; Wack, M.E.; Denys, G.A. (2002) Levofloxacin treatment failure in a patient with fluoroquinoloneresistant Streptococcus pneumoniae pneumonia. Pharmacotherapy, 22, 395-399.

39. Kiffer, C.; Hsiung, A.; Oplustil, C.; Sampaio, J.; Sdagami, E.; Turner, P.; Mendes, C. (2005). Antimicrobial susceptibility of Gram-negative bacteria in Brazilian hospitals: the MYSTIC Program Brazil 2003. Braz. J. Infect. Dis., 9, 216-224.

40. Kiffer, C.R.V.; Kuti, J.L.; Mendes, C.M.F.; Oplustil, C.P.; Amarante, J.B.; Biancalana, M.L.; Xavier, N.; Nicolau, D.P. A pharmacodynamic strategy to optimize empirical antibiotic therapy for gram-negative bacteria in a Brazilian intensive care unit. Brazilian J. Infect. Dis., in press.

41. Kiffer, C.R.V.; Mendes, C.; Kuti, J.L.; Nicolau, D.P. (2004) Pharmacodynamic comparisons of antimicrobials against nosocomial isolates of Escherichia coli, Klebsiella pneumoniae, Acinetobacter baumannii, and Pseudomonas aeruginosa from the MYSTIC surveillance program: the OPTAMA Program, South America 2002. Diagn. Microbiol. Infect. Dis., 49, 109-116.

42. Kuti, J.L.; Dandekar, P.K.; Nightingale, C.H.; Nicolau, D.P. (2003) Use of Monte Carlo simulation to design an optimized pharmacodynamic dosing strategy for meropenem. J. Clin. Pharmacol., 43, 1116-1123.

43. Kuti, J.L.; Moss, K.M.; Nicolau, D.P.; Knauft F.R. (2004). Empiric treatment of multidrug-resistant Burkholderia cepacia lung 
exacerbation in a patient with cystic fibrosis: application of pharmacodynamic concepts to meropenem therapy. Pharmacotherapy, 24: $1641-1645$

44. Kuti, J.L.; Nicolau, D.P. (2005). Making the most of surveillance studies: summary of the OPTAMA Program. Diagn. Microbiol. Infect. Dis., 53, 281-287.

45. Lacy, M.K.; Lu, W.; Xu, X.; Tessier, P.R.; Nicolau, D.P.; Quintiliani, R.; Nightingale, C.H. (1999). Pharmacodynamic comparisons of levofloxacin, ciprofloxacin, and ampicillin against Streptococcus pneumoniae in an in vitro model of infection. Antimicrob. Agents Chemother., 43, 672-677.

46. Li, C.; Du, X.; Kuti, J.L.; Nicolau, D.P. (2005). Clinical pharmacodynamics of meropenem in adult patients with lower respiratory tract infections [abstract A-1147]. In: Abstracts of the $45^{\text {th }}$ Interscience Conference on Antimicrobial Agents and Chemotherapy. Am. Soc. Microbiol., Washington D.C., p.20.

47. Li, J.; Turnidge, J.; Milne, R.; Nation, R.L.; Coulthard, K. (2001). In vitro pharmacodynamic properties of colistin and colistin methanesulfonate against Pseudomonas aeruginosa isolates from patients with cystic fibrosis. Antimicrob. Agents Chemother, 45, 781-785.

48. Linares, J. (2001). The VISA/GISA problem: therapeutic implications. Clin Microbiol. Infect., 7 (Suppl 4), 8-15.

49. Lodise, T.P.; Lomaestro, B.M.; Drusano, G.L. (2004). Evaluation of the clinical and economic implications of an extended infusion dosing strategy of piperacillin/tazobactam for Pseudomonas aeruginosa infections [abstract O-1617]. In: Abstracts of the 44th Interscience Conference on Antimicrobial Agents and Chemotherapy. Am. Soc. Microbiol., Washington, DC, p.446.

50. Lodise, T.P.; Preston, S.; Bhargava, V.; Bryskier, A.; Nusrat, R.; Chapel, S.; Rangaraju, M.; Drusano, G.L. (2005). Pharmacodynamics of an 800-mg dose of telitromycin in patients with communityacquired pneumonia caused by extracellular pathogens. Diagn. Microbiol. Infect. Dis., 52, 45-52.

51. Louie, A.; Kaw, P.; Liu, W.; Jumbe, N.; Miller, M.H.; Drusano, G.L. (2001). Pharmacodynamics of daptomycin in a murine thigh model of Staphylococcus aureus infection. Antimicrob. Agents. Chemother, $45,845-851$.

52. Ludwig, E.; Konkoly-Thege, M.; Kuti, J.L.; Nicolau, D.P. (2006). Optimizing antibiotic dosing regimens based on pharmacodynamic target attainment against Pseudomonas aeruginosa collected in Hungarian Hospitals. Int. J. Antimicrob. Agents., 28, 433-438.

53. Maglio, D.; Ong, C.; Banevicius, M.A.; Nightingale, C.H.; Nicolau, D.P. (2004). Determination of the in vivo pharmacodynamic profile of cefepime against extended-spectrum- $\beta$-lactamase-producing Escherichia coli at various inocula. Antimicrob. Agents Chemother, 48, 1941-1947.

54. Mattoes, H.M.; Kuti, J.L.; Drusano, G.L.; Nicolau, D.P. (2004). Optimizing antimicrobial pharmacodynamics: dosage strategies for meropenem. Clin. Therapeutics, 26, 1187-1198.

55. Meagher, A.; Passarell, J.; Cirincione, B.; Van Wart, S.; Liolios, K.; Babinchak, T.; Ellis-Grosse, E.J.; Ambrose, P.G. (2005). Exposureresponse analysis of the efficacy of tigecycline in patients with complicated skin and skin-structure infections [abstract P1184]. Clin. Microbiol. Infect., 11 (Suppl 2), 373-374.

56. Mendes, C.M.F.; Marin, M.E.; Quinones, F.; Sifuentes-Osornio, J.; Siller, C.C.; Castanheira, M.; Zoccoli, C.M.; Lopez, H.; Sucari, A.; Rossi, F.; Angulo, G.B.; Segura, A.J.; Starling, C.; Mimica, I.; Felmingham, D. (2003). Antibacterial resistance of communityacquired respiratory tract pathogens recovered from patients in Latin America: results from the PROTEKT surveillance study (19992000). Braz. J. Infect. Dis., 7, 44-61.

57. Moise, P.A.; Forrest, A. Bhavnani, S.M.; Birmingham, M.C.; Schentag, J.J. (2000). Area under the inhibitory curve and a pneumonia scoring system for predicting outcomes of vancomycin therapy for respiratory infections by Staphylococcus aureus. Am. J. HealthSyst. Pharm., 57, 84-89.

58. Moise-Broder, P.A.; Forrest, A.; Birmingham, M.C.; Schentag, J.J. (2004). Pharmacodynamics of vancomycin and other antimicrobials in patients with Staphylococcus aureus lower respiratory tract infections. Clin. Pharmacokinet., 43, 925-942.

59. Moore, R.D.; Lietman, P.S.; Smith, C.R. (1987). Clinical response to aminoglycoside therapy: importance of the ratio of peak concentration to minimal inhibitory concentration. J. Infect. Dis., 155, 93-99.

60. Moore, R.D.; Smith, C.R.; Lietman, P.S. (1984). The association of aminoglycoside plasma levels with mortality in patients with gramnegative bacteremia. J. Infect. Dis., 149, 443-448.

61. Mutnick, A.H.; Biedenbach, D.J.; Jones, R.N. (2003). Geographic variations and trends in antimicrobial resistance among Enterococcus faecalis and Enterococcus faecium in the SENTRY Antimicrobial Surveillance Program (1997-2000). Diagn. Microbiol. Infect. Dis., 46, 63-68

62. Nicolau, D.P.; Freeman, C.D.; Belliveau, P.P.; Nightingale, C.H.; Ross, J.W.; Quintiliani, R. (1995). Experience with a once-daily aminoglycoside program administered to 2,184 adult patients. Antimicrob. Agents Chemother, 39, 650-655.

63. Passarell, J.A.; Liolios, K.; Meagher, A.K.; Cirincione, B.B.; Van Wart, S.A.; Babinchak, T.; Ellis-Grosse, E.J.; Ambrose, P.G. (2005). Exposure-response analysis of the efficacy of tigecycline in patients with complicated intra-abdominal infections [abstract A-1155]. In: Abstracts of the $45^{\text {th }}$ Interscience Conference on Antimicrobial Agents and Chemotherapy. American Society for Microbiology, Washington D.C., p. 22 .

64. Preston, S.L.; Drusano, G.L.; Berman, A.L.; Fowler, C.L.; Chow, A.T.; Dornseif, B.; Reichl, V.; Natarajan, J.; Corrado, M. (1998). Pharmacodynamics of levofloxacin: a new paradigm for early clinical trials. JAMA, 279, 125-129.

65. Rybak, M.J. (2006). The pharmacokinetic and pharmacodynamic properties of vancomycin. Clin. Infect. Dis., 42, S35-S39.

66. Sader, H.S.; Castanheira, M.; Mendes, R.E.; Toleman, M.; Walsh, T.R.; Jones, R.N. (2005). Dissemination and diversity of metallo- $\beta$ lactamases in Latin America: report from the SENTRY Antimicrobial Surveillance Program. Int. J. Antimicrob. Agents, 25, 57-61.

67. Sader, H.S.; Jones, R.N.; Andrade-Baiocchi, S.; Biedenbach, D.J. (2003). Four-year evaluation of frequency of occurrence and antimicrobial susceptibility patterns of bacteria from bloodstream infections in Latin America medical centers. Diagn. Microbiol. Infect. Dis., 44, 273-280.

68. Sader, H.S.; Jones R.N.; Stilwell, M.G.; Dowzicky, M.J.; Fritsche, T.R. (2005). Tigecycline activity tested against 26,474 bloodstream infection isolates: a collection from 6 continents. Diagn. Microbiol. Infect. Dis., 52, 181-186.

69. Sakoulas, G.; Moise-Broder, P.A.; Schentag, J.J.; Forrest, A.; Moellering, R.C.; Eliopoulos, G.M. (2004). Relationship of MIC and bactericidal activity to efficacy of vancomycin for treatment of methicillin-resistant Staphylococcus aureus bacteremia. J. Clin. Microbiol., 42, 2398-2402.

70. Sprandel, K.A.; Drusano, G.L.; Hecht, D.W.; Rotschafer, J.C.; Danziger, L.H.; Rodvold, K.A. (2006). Population pharmacokinetic modeling and Monte Carlo simulation of varying doses of intravenous metronidazole. Diagn. Microbiol. Infect. Dis., 55, 303-309.

71. Stelling, J.M.; Travers, K.; Jones, R.N.; Turner, P.J.; O’Brien, T.F.; Levy, S.B. (2005). Integrating Escherichia coli antimicrobial susceptibility data from multiple surveillance programs. Emerg. Infect. Dis., 11, 873-882.

72. Tam, V.H.; Louie, A.; Deziel, M.R.; Liu, W.; Leary, R.; Drusano, G.L. (2005). Bacterial-population responses to drug-selective pressure: examination of garenoxacin's effect on Pseudomonas aeruginosa. J. Infect. Dis., 192, 420-428. 
73. Tam, V.H.; Louie, A.; Lomaestro, B., Drusano, G.L. (2003). Integration of population pharmacokinetics, a pharmacodynamic target, and microbiologic surveillance data to generate a rational empiric dosing strategy for cefepime against Pseudomonas aeruginosa. Pharmacotherapy, 23, 291-295.

74. Tam, V.H.; McKinnon, P.S.; Akins, R.L.; Rybak, M.J.; Drusano, G.L. (2002). Pharmacodynamics of cefepime in patients with Gramnegative infections. J. Antimicrob. Chemother, 50, 425-428.

75. Tam, V.H.; Schilling, A.N.; Vo, G.; Kabbara, S.; Kwa, A.L.; Wiederhold, N.P.; Lewis, R.E. (2005). Pharmacodynamics of polymyxin B against Pseudomonas aeruginosa. Antimicrob. Agents Chemother., 49, 3624-3630.

76. Tessier, P.R.; Mattoes, H.M.; Dandekar, P.K.; Nightingale, C.H.; Nicolau, D.P. (2005). Pharmacodynamic profile of telithromycin against macrolide- and fluoroquinolone-resistant Streptococcus pneumoniae in a neutropenic mouse thigh model. Antimicrob. Agents Chemother., 49, 188-194.

77. Tognim, M.C.; Andrade, S.S.; Silbert, S.; Gales, A.C.; Jones, R.N.; Sader, H.S. (2004). Resistance trends of Acinetobacter spp. in Latin America and characterization of international dissemination of multidrug resistant strains: five-year report of the SENTRY Antimicrobial Surveillance Program. Int. J. Infect. Dis., 8, 284-291.
78. Turnidge, J.D. (1998). The pharmacodynamics of $\beta$-lactams. Clin Infect. Dis., 27, 10-22.

79. Unal, S.; Garcia-Rodriquez, J.A. (2005). Activity of meropenem and comparators against Pseudomonas aeruginosa and Acinetobacter spp. isolated in the MYSTIC Program, 2002-2004. Diagn. Microbiol. Infect. Dis., 53, 265-271.

80. Van Ogtrop, M.L.; Andes, D.; Stamstad, T.J.; Conklin, B.; Weiss, W.J.; Craig, W.A.; Vesga, O. (2000). In vivo pharmacodynamic activities of two glycylcyclines (GAR-936) and WAY 152,288) against various gram-positive and gram-negative bacteria. Antimicrob. Agents Chemother., 44, 943-949.

81. Villegas, M.V.; Correa, A.; Perez, F.; Miranda, M.C.; Zuluaga, T.; Quinn, J.P. (2004). Prevalence and characterization of extendedspectrum $\beta$-lactamases in Klebsiella pneumoniae and Escherichia coli isolates from Colombian hospitals. Diagn. Microbiol. Infect. Dis., 49, 217-222.

82. Wallace, A.W.; Jones, M.; Bertino, J.S. (2002). Evaluation of four once-daily aminoglycoside dosing nomograms. Pharmacotherapy, 22, 1077-1083.

83. Wright, D.H.; Brown, G.H.; Peterson, M.L.; Rotschafer, J.C. (2000) Application of fluoroquinolone pharmacodynamics. J. Antimicrob. Chemother., 46, 669-683. 